\title{
Análise de erros no ensino de Matemática: uma experiência realizada no IFBA Campus Eunápolis na disciplina de Estágio IV
}

Danilo do Nascimento de Jesus

\section{Resumo}

Este relato traz uma experiência de um curso de formação de professores realizada no IFBA campus Eunápolis-BA no ano de 2016. O público alvo foram professores da rede municipal da cidade e o curso tinha como tema análise de erros no ensino de Matemática. O objetivo do curso era oferecer formação continuada a estes docentes propondo um trabalho com esta metodologia, tanto no ensino como na pesquisa, de forma que estes docentes adquirissem outro olhar para o ensino de Matemática, sobretudo para os erros dos estudantes nesta disciplina. O curso aconteceu concomitantemente a disciplina de estágio IV, sendo executado em três etapas. Ao final do curso, verificou-se que os professores cursistas não conheciam a metodologia trabalhada, e que esta seria importante para a formação continuada destes educadores como educadores matemáticos.

Palavras-chave: Formação de Professores. Análise de Erros. Educação Matemática 


\section{Analysis of errors in teaching Mathematics: an experience carried out at the IFBA Campus Eunápolis in the subject of Estágio IV}

Danilo do Nascimento de Jesus

\section{Abstract}

This report brings an experience of a teacher training course held at the IFBA campus Eunápolis-BA in 2016. The target audience were teachers from the city's municipal network and the course had as its theme error analysis in Mathematics teaching. The aim of the course was to offer continuing education to these teachers by proposing work with this methodology, both in teaching and in research, so that these teachers would acquire another look at the teaching of Mathematics, especially the errors of students in this discipline. The course took place concomitantly with the discipline of Wstágio IV, being executed in three stages. At the end of the course, it was found that the course teachers did not know the methodology worked, and that this would be important for the continued training of these educators as mathematical educators.

Keywords: Teacher Training. Analysis of Errors. Mathematics Education 


\section{Introdução}

A experiência que passarei a relatar aqui aconteceu no ano de 2016 no Instituto Federal da Bahia Campus Eunápolis- IFBA Eunápolis, atrelada a disciplina de estágio IV, tendo como público alvo professores da rede Municipal da cidade de Eunápolis-Bahia. A ideia de ofertar este curso a professores da rede municipal se justificou na medida em que a maioria do público (estudantes) atendido pelo Instituto Federal da Bahia- IFBA na educação básica e profissional era oriunda da rede municipal, e esses estudantes chegam ao ensino médio com sérios problemas de aprendizagem matemática, identificados a partir da metodologia de análise de erros em Matemática.

Foi feita uma seleção via edital de oito professores da rede municipal de Eunápolis, mesma quantidade de alunos matriculados na disciplina de estágio IV. Cada professor cursista ficaria com um estudante estagiário, com vistas a desempenharem as atividades do curso que ocorreriam na segunda e terceira etapas do curso. Estas etapas corresponderam respectivamente ao planejamento e elaboração do teste como instrumento de coleta de dados, e a análise dos dados com a aplicação da metodologia. Na primeira etapa foi feita uma discussão teórica com a temática análise de erros no ensino de Matemática, a partir da leitura e discussão de cinco artigos, que serão explicitados no quadro abaixo, que também descreverá os objetivos propostos para cada texto além do planejamento dessas discussões.

Quadro 1- Descrição dos textos no $1^{\circ}$ módulo

\begin{tabular}{|c|c|c|}
\hline $\mathbf{O S}$ & D & $\begin{array}{l}\text { nento das } \\
\text { issões }\end{array}$ \\
\hline $\begin{array}{l}\text { Retrospectiva histórica e } \\
\text { perspectivas atuais da análise } \\
\text { de erros em educação } \\
\text { Matemática. }\end{array}$ & $\begin{array}{l}\text { Fazer uma abordagem } \\
\text { histórica do desenvolvimento } \\
\text { da metodologia, bem como } \\
\text { apresentar os principais } \\
\text { autores com contribuíram para } \\
\text { este desenvolvimento. }\end{array}$ & $\begin{array}{l}\text { Os alunos estagiários } \\
\text { apresentaram os textos com a } \\
\text { condução do debate pelo } \\
\text { professor ministrante do curso. }\end{array}$ \\
\hline $\begin{array}{l}\text { Anál } \\
\text { de pr } \\
\text { de e } \\
\text { licen }\end{array}$ & $\begin{array}{l}\text { a análise de erros na } \\
\text { va da resolução de } \\
\text { s em uma disciplina } \\
\end{array}$ & $\begin{array}{l}\text { Os alunos estagiários } \\
\text { apresentaram os textos com a } \\
\text { condução do debate pelo } \\
\text { professor ministrante do curso. }\end{array}$ \\
\hline $\begin{array}{l}\mathrm{O} \text { erro como ponte para a } \\
\text { aprendizagem de equações: } \\
\text { caso de Maria. }\end{array}$ & $\begin{array}{l}\text { Analisar o trabalho de } \\
\text { pesquisa com análise de erros } \\
\text { em tópicos matemáticos no } \\
\text { ensino fundamental. }\end{array}$ & $\begin{array}{l}\text { Os alunos estagiários } \\
\text { apresentaram os textos com a } \\
\text { condução do debate pelo } \\
\text { professor ministrante do curso. }\end{array}$ \\
\hline $\begin{array}{l}\text { Exemplos de classificação e } \\
\text { análise de erros: uma pesquisa } \\
\text { com calouros de cursos } \\
\text { superiores. }\end{array}$ & $\begin{array}{l}\text { análise } \\
\text { ior. }\end{array}$ & $\begin{array}{l}\text { Os alunos estagiários } \\
\text { apresentaram os textos com a } \\
\text { condução do debate pelo } \\
\text { professor ministrante do curso. }\end{array}$ \\
\hline $\begin{array}{l}\text { Análise de conteúdo das } \\
\text { respostas: uma visão da } \\
\text { metodologia empregada }\end{array}$ & $\begin{array}{l}\text { de dados con } \\
\text { ise de erros } n \\
\text { ática }\end{array}$ & $\begin{array}{l}\text { Os alunos estagiários } \\
\text { apresentaram os textos com a } \\
\text { condução do debate pelo } \\
\text { professor ministrante do curso. }\end{array}$ \\
\hline
\end{tabular}


Na segunda etapa, os professores cursistas e os estudantes estagiários foram a campo para verificar os erros cometidos pelos alunos em conteúdos específicos de Matemática. Foi construído um teste para realizar a coleta de dados, estruturado como o objetivo de identificar e categorizar os erros. Por fim, na terceira etapa, cada professor juntamente com o seu estagiário realizou a socialização da pesquisa realizada nas escolas bem como possíveis intervenções a serem feitas a partir das informações coletadas.

\section{$1^{\circ}$ Módulo do Curso: Discussão Teórica da Análise de Erros}

O primeiro módulo do curso contou com 30 horas de discussão teórica. Esta carga horária foi dividida entre presencial e a distância, sendo 20 horas presenciais e 10 horas à distância utilizando a plataforma de aprendizagem virtual Moodle7\% Os encontros presenciais tinham quatro horas cada, e as aulas virtuais 5 horas, sendo que estas eram trabalhadas a partir de fóruns. Os estudantes da disciplina de estágio IV, com a orientação do professor regente da disciplina, procederam às apresentações dos textos selecionados previamente, e o debate ocorria na medida em que os textos eram apresentados.

A discussão teórica teve como objetivo dar embasamento teórico aos professores cursistas na metodologia de ensino análise de erros no ensino de Matemática, e capacitar os professores a analisar o erro dos seus alunos não como obstáculo, mas como uma oportunidade de ensinar a partir dele. Neste contexto, o aluno tem participação ativa no processo e, portanto,

Dentro de um enfoque construtivista é dever do professor assegurar um ambiente dentro do qual os alunos possam reconhecer e refletir sobre suas próprias idéias; aceitar que outras pessoas expressem pontos de vista diferentes dos seus, mas igualmente válidos e possam avaliar a utilidade dessas idéias em comparação com as teorias apresentadas pelo professor. (JÓFILI, 2002, p.196)

Por outro lado, Jófili também destaca, a partir do enfoque construtivista e,

Considerando que a responsabilidade final pela própria aprendizagem pertence a cada aluno, a tarefa do professor é encorajá-los a verbalizarem suas idéias, ajudá-los a tornarem-se conscientes de seu próprio processo de ensino e aprendizagem e relacionarem suas experiências prévias às situações sobre estudo. Uma construção crítica do conhecimento está associada com questionamentos: seja para entender o pensamento do aluno, seja para promover uma aprendizagem conceitual. (JÓFILI, 2002, p.198)

Pensando na perspectiva da análise de erros, para Cury (2005), a análise da produção escrita dos estudantes em qualquer nível é uma possibilidade de trabalho que pode ser considerada sob o ponto de vista da investigação ou do ensino. Ainda segundo a autora, a

${ }^{7}$ Em inglês, Modular Object Oriented Dynamic Learning Envirionment foi desenvolvido pelo educador e analista de sistema Martin Dougiamas, em Perth, na Austrália, no final da década de 1990. ISSN 2526-2882 
análise de erros no ensino de Matemática tem se desenvolvido como uma importante abordagem metodológica de ensino e de pesquisa em educação Matemática.

Porém, em âmbitos gerais, os erros cometidos pelos alunos são vistos frequentemente como uma falha, algo que caracteriza um fracasso no processo educativo. Este procedimento originou-se a partir do Behaviorismo ${ }^{8}$ e vem sendo difundido ao longo dos anos, o que corroborou para que professores de Matemática desempenhassem suas atividades no sentido de eliminar os erros encontrados sem uma reflexão sobe a origem dos mesmos (Cury, 1995). Logo, segundo Borasi (1996 apud CURY, 2007), ao convidar os professores a abandonarem a concepção de ensino como transmissão de informações, indica o desenvolvimento de ambientes de aprendizagem, em que é possível encaminhar os alunos para atividades de exploração.

Como Freire (1977, apud Jófili, 2002) diz, nós deveríamos não importar ideias, mas recriá-las. Dessa forma, um ensino construtivista crítico não poderia ser entendido como receitas prontas a serem seguidas, mas como sugestões a serem examinadas pelos professores. Tal criticismo é crucial em todos os níveis da educação e deve estar presente, particularmente, durante programas de formação de professores, devido ao seu efeito multidisciplinar.

Ao final do $1^{\mathrm{o}}$ módulo do curso, verificou-se que os professores cursistas não tiveram acesso a essa metodologia de ensino e pesquisa durante a sua formação inicial, e, portanto, nunca usaram tal metodologia durante as aulas. Todos os professores relataram, após a discussão teórica, que estavam curiosos para verificar como seriam as aulas utilizando esta metodologia de ensino.

\section{$2^{\circ}$ Módulo: Pesquisa de Campo}

Após a realização do debate teórico, cada professor cursista com seu respectivo estagiário elaborou uma atividade que continha duas questões cada, para serem aplicadas nas respectivas turmas dos professores cursistas nas escolas municipais. A atividade tinha como objetivo analisar os erros cometidos pelos estudantes, utilizando a metodologia de análise de conteúdo de Laurence Bardim. Cury (2011) com base na análise de conteúdo de Bardin (1979, apud Cury, 2007) define a análise de conteúdos em três etapas: Pré-análise, exploração do material e tratamento dos resultados.

Na pré-análise, as respostas são classificadas em corretas, incorretas e em branco e, desta forma, estes dados compõem o corpus da em que será feito a análise de conteúdo. $\mathrm{Na}$ segunda etapa, o material é explorado com maior ênfase, e as respostas incorretas são classificadas em categorias com a finalidade de agrupar respostas semelhantes. Por fim, na

8 O Behaviorismo - do termo inglês behaviour ou do americano behavior, significando conduta, comportamento - é o conjunto das teorias psicológicas que postulam o comportamento como o mais adequado objeto de estudo da Psicologia. 
terceira etapa, são elaborados textos que sintetizam os dados característicos de cada classe de respostas, elucidando de modo geral os erros cometidos depois da aplicação do teste. Foram elaborados oito testes, dos quais três tinham como tópico a potenciação, três continham expressões numéricas, um com equação do $1^{\circ}$ grau e outro com geometria. Esta etapa do curso teve um total de 30 horas, e subdividiu-se em: elaboração do teste, aplicação do teste e tratamento dos dados.

\section{$3^{\circ}$ Módulo: Apresentação dos resultados e algumas reflexões}

No terceiro módulo do curso, os professores cursistas e seus respectivos estagiários procederam à apresentação e discussão dos dados. Apresento aqui uma síntese dos resultados, bem como uma reflexão sobre os mesmos. Cada teste continha duas questões, e será apresentada aqui uma questão de cada tópico, bem como uma categorização de erro (exceto no tópico equações). Nos testes que continham o tópico potenciação, uma das questões de pesquisa foi:

Simplifique as expressões abaixo:
a) $40-\left[5^{2}-\left((-2)^{3}-5\right)\right]$
b) $\left(-\frac{2}{3}\right)^{2}+\left(2^{3}-3^{2}\right)^{2}$

Esta questão foi a que apresentou o maior número de erros, mais precisamente: 19 erros, três acertos e sete em branco, num total de 29. Depois de corrigidos os testes foi possível estabelecer algumas categorias de erros, dentre os quais destaco:

\section{Erros relacionados à definição ou a propriedades de potenciação}

Nesta categoria foram classificados os alunos que mostraram não dominar a definição ou as propriedades de potenciação, por exemplo, o primeiro aluno tentou multiplicar a base pelo expoente e o segundo aluno aplicou a propriedade de expoente de base fracionária de maneira equivocada. Veja a figura 1 abaixo.

Figura 1: Erros de Potênciação
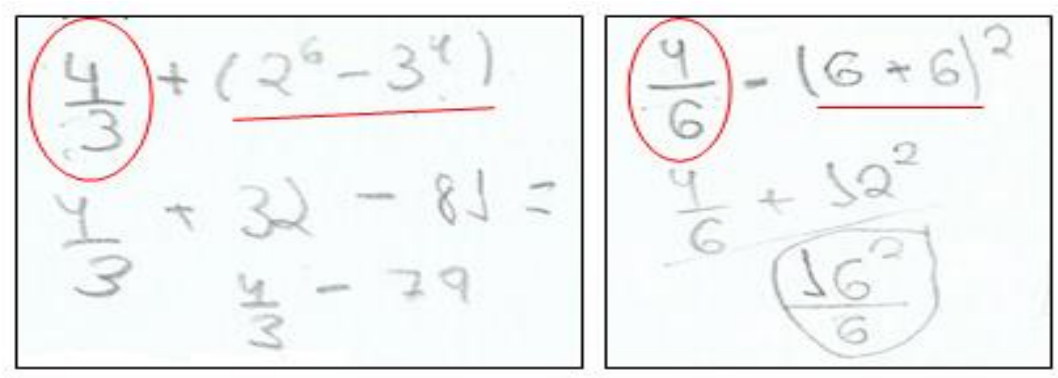

Fonte: Autor

Em relação ao tópico equação do $1^{0}$ grau, a questão escolhida para discussão neste relato foi: O triplo de um número, menos 25, é igual ao próprio número, mais 55. Que número 
é este? Esta questão, de um total de 21 estudantes, não teve nenhum acerto, 14 respostas erradas e 7 em branco. Dentre os erros cometidos pelos estudantes, destaco aqui dois:

\section{Erros de Álgebra que têm origem na Aritmética}

Figura 2: Erros de álgebra

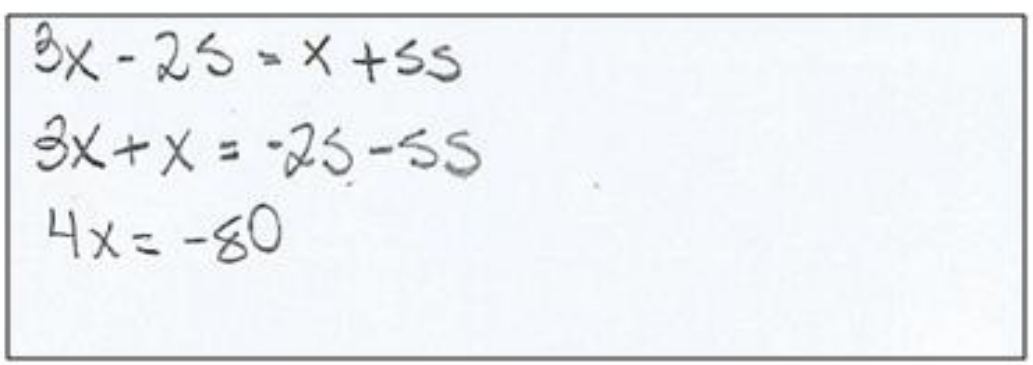

Fonte: Autor

Este exemplo nos mostrou que o estudante entendeu o enunciado, pois montou a equação corretamente. Mas ao resolver a equação, não mudou as operações dos termos ao mudá-los de lado na equação.

\section{Erros de procedimento. Uso de fórmulas ou regras indevidamente.}

Figura 3: Erros de álgebra

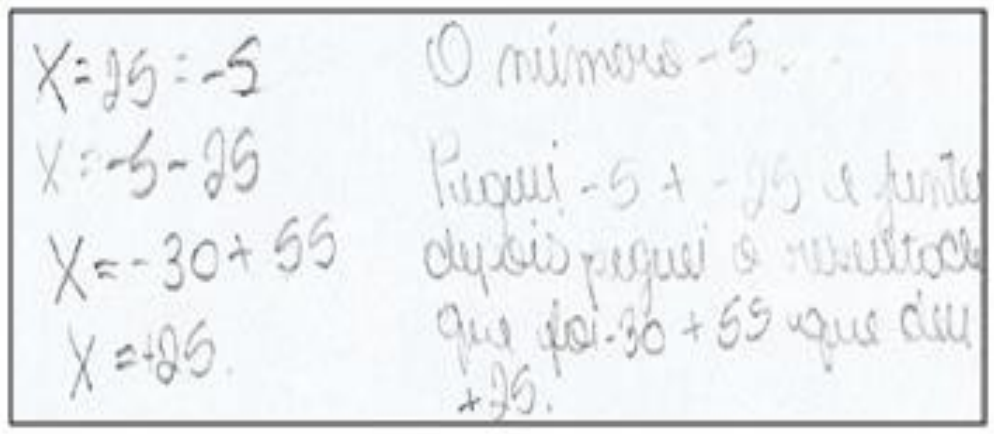

Fonte: Autor

Nesta tentativa de solução, o aluno não compreendeu o enunciado, e não utilizou o procedimento correto para solucionar o problema. Esta é uma dificuldade comum encontrada entre os estudantes, compreender e interpretar problemas matemáticos, ou qual ferramenta matemática utilizar para resolver o problema.

No tópico geometria, a questão escolhida para ser relatada aqui foi:

Analise a figura ao lado e responda:

Qual o número de vértices:

Qual o número de faces:

Qual o número de Arestas:

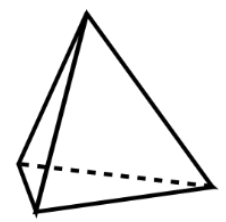


Figura 4: Erros de geometria

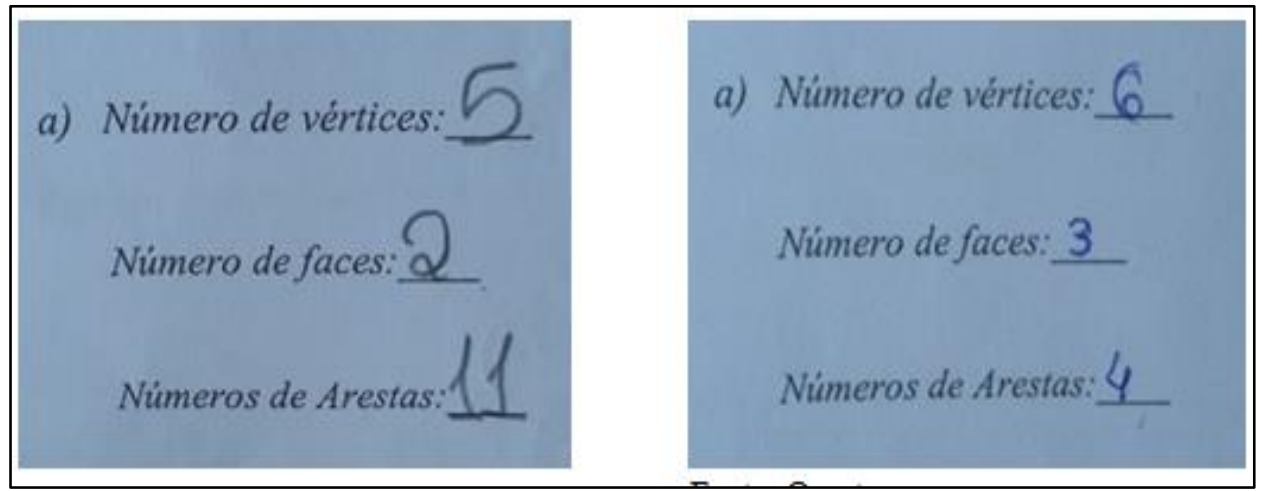

Fonte: Autor

\section{Erro de identificação dos elementos que constituem um sólido geométrico}

De um total de 17 alunos, nenhum apresentou a resposta correta. No exemplo acima, os alunos não conseguem identificar o número de vértices, arestas e faces, mostrando claramente que não compreendem o conceito de sólido geométrico e os elementos que o constituem.

No tópico expressão numérica uma das questões do teste foi: Responda a expressão abaixo: $(\mathbf{1 0}-\mathbf{4})-(\mathbf{9}-\mathbf{8})+3$

\section{Erro na eliminação dos parênteses ou jogo do sinal}

Figura 5: Erros de expressão numérica

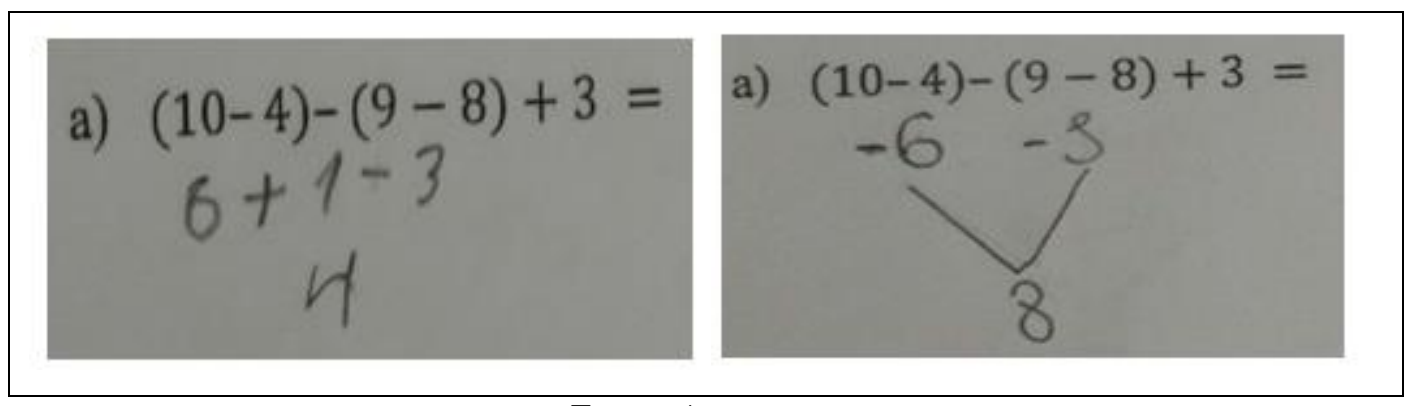

Fonte: Autor

Nesta categoria, os alunos erram ao resolver as operações dentro dos parênteses e ao operarem com o sinal de fora, por isso, um erro ocasionou o outro. Podemos observar na resolução do aluno A2, que operou $(\mathbf{9}-\mathbf{8})=\mathbf{1}$, mas não operou com o sinal de fora. Já o aluno A13 errou na eliminação dos parênteses em $\mathbf{1 0}-\mathbf{4}=-\mathbf{6}$, mas acertou $-(\mathbf{9}-\mathbf{8})=-\mathbf{1}$.

\section{Considerações Finais}

Ao final das apresentações, ficou evidenciado para os professores participantes a importância de utilizar esta metodologia em suas aulas, pois tendo conhecimento dos erros 
cometidos pelos estudantes bem como suas categorias, eles poderão propor atividades de intervenção, incluindo o aluno no processo de discussão deste erro, fazendo com que ele participe do processo de construção de seu próprio conhecimento. Um ponto considerado negativo no curso foi não prever um trabalho de intervenção a partir dos erros categorizados e unitarizados. Mas os professores foram encorajados para, ao voltarem as suas salas de aula, propor este trabalho intervencionista a partir da pesquisa realizada.

Para os estagiários que cursavam a disciplina de estágio supervisionado em Matemática IV, foi uma experiência inovadora, pois este trabalho permitiu um alinhamento entre ensino, pesquisa e extensão. Ensino pois os estudantes ministraram aulas tanto no curso de extensão como nas escolas do município, extensão pois o curso foi destinado a professores da comunidade externa do IFBA e pesquisa, visto que houve uma investigação a partir de pressupostos teóricos. Desta forma, o estágio permitiu que estes futuros professores vivenciassem a prática pedagógica de maneira completa.

Além disso, a participação dos docentes das escolas municipais permitiu uma integração entre o ensino superior e o ensino básico, possibilitando trabalhar ensino e pesquisa e propondo possíveis soluções para os erros encontrados. Outro ponto observado foram as dificuldades com relação aos conteúdos pesquisados, verificando a deficiência no ensino de Matemática nas escolas públicas. Diante deste contexto, torna-se importante trabalhar com metodologias que permitam a reflexão sobre o processo de ensino e aprendizagem, como a análise de erros no ensino de Matemática.

\section{Referências}

BEHAVIORISMO

Significado

do.

Disponível

em: < https://www.significados.com.br/behaviorismo>. Acesso em 20 de Março de 2016.

CURY, H. N. Retrospectiva histórica e perspectivas atuais da análise de erros em Educação Matemática. Revista Zetetiké, Campinas, Brazil, v.3, n.4, p. 39-50, 1995. Disponível em: <http://ojs.fe.unicamp.br/ged/index.php/zetetike/index>. Acesso em: 02 de fevereiro de 2016

CURY, H. N. Análise de conteúdo das Respostas: uma visão da metodologia empregada. In: CURY, H. N. Análise de Erros: o que podemos aprender com as respostas dos alunos. Belo Horizonte: Autêntica, 2007, p. 61-78.

CURY, H. N.; R., A. J.; Müller, T. J. Explorando erros na resolução de equações: um caminho para a formação do professor de Matemática. Revista Iberoamericana de Educación Matemática, n.28, p. 143-157. Dezembro de 2011. Disponível em: <http://www.fisem.org/www/union/revista28.php>. Acesso em: 10 de fevereiro de 2016 
CURY, H. N. Exemplos de Classificação de Erros: uma pesquisa com calouros de cursos superiores. In. Análise de Erros: o que podemos aprender com as respostas dos alunos. Belo Horizonte: Autêntica, 2007. p. 49-60. (Coleção Tendências em Educação Matemática).

FREIRE, P. Ação Cultural para a liberdade. (cultural action for freedom) 2.ed. Rio de Janeiro: Paz e Terra, 1977.

JÓFILI, Z. Piaget, Vygotsky, Freire e a Construção do conhecimento na Escola. Educação: Teorias e Práticas, Recife, Brazil, v. 2, n.2, p. 191-208, 2002.

VAle, L.; FERrEirA, R. A.; SANTOS, L. O Erro como Ponte para Aprendizagem de Equações: o caso de Maria. [S.E.], [S.D.]. Disponível em: <http://cmup.fc.up.pt/cmup/eiem/grupos/documents/24.Vale_Ferreira\%20e\%2oS antos.pdf $>$. Acesso em: 24 de abril de 2017.

\section{Biografia Resumida}

Danilo do Nascimento de Jesus: Licenciado em Matemática (UNASP - São Paulo), Especialista em Matemática e Estatística (UFLA - Lavras), Mestrando no programa de pós graduação em ensino de ciências exatas (UNIVATES - Lajeado), Professor do Instituto Federal da Bahia Campus Eunápolis.

Lattes: http://lattes.cnpq.br/2769218355565833

Contato: danilo.matematica21@gmail.com 